\title{
Processo de avaliação da aprendizagem em curso de Odontologia
}

\author{
É essencial que haja uma discussão acerca de como a aprendizagem \\ deve ser avaliada nos cursos de graduação.
}

Marcos Tarciso Masetto*, Andréa Sales do Prado**

* Professor Titular da Pontifícia Universidade Católica de São Paulo.

*** Mestranda em Educação: Currículo - Pontifícia Universidade

Católica de São Paulo.

$\mathbf{0}$ tema avaliação sempre é instigador quando dialogamos com professores por vários motivos: seja pela insatisfação que causa em alunos e professores; seja pelos sentimentos que produz (tensão, medo, pavor, insegurança, arbitrariedade, injustiça nos alunos; insegurança, certezas, poder, disciplina, indisciplina, controle, objetividade, subjetividade, justiça, injustiça nos professores); seja pelas conseqüências que a avaliação traz: aprovação ou reprovação, formação de profissionais competentes ou incompetentes, responsabilidade social pela colocação de profissionais que atendam às necessidades da sociedade, valorização ou não de disciplinas conforme o índice de reprovação (indicador da "seriedade e nível" da disciplina).

Do ponto de vista teórico são outras questões complexas a serem consideradas: avaliação de produto e/ou de processo? Avaliação final classificatória? Avaliação contínua durante o processo de aprendizagem? Distinguir entre processo de avaliação e técnicas avaliativas, hetero e auto-avaliação.

Todas estas provocações nos levam a refletir sobre o processo de avaliação em seu conceito e em sua história, para posteriormente analisarmos a possibilidade de se implantar um novo processo avaliativo em cursos de Odontologia.

\section{PROCESSO de AVAlIAÇÃO: CONCEITO E HISTÓRIA}

A avaliação pode ser considerada como um processo que faz parte da nossa vida cotidiana. Apesar de no dia-a-dia não serem necessários instrumentos formais, estamos constantemente atribuindo juízos de valor, a tudo o que nos rodeia.
Neste estudo, iremos focar a avaliação dentro do sistema educacional, especificamente na aprendizagem, pois é justamente nessa área que ela vem produzindo efeitos mais marcantes dentro e fora do contexto das instituições educacionais, com repercussões de caráter ético, político e pedagógico.

No cenário educacional, historicamente, a palavra avaliação tem estado vinculada a uma dimensão classificatória de atribuir juízo de valor, de julgamento, de regulamentação, utilizada como um instrumento de poder e controle que aprova ou reprova. Transforma em valor absoluto o que pode ser relativo, é usado como um artifício de punição, ocorrendo a partir de um currículo pré-definido reduzindo-se a uma medida que por sua vez é traduzida através de provas ou verificação de resultados.

Este artigo tem por objetivo mostrar um outro olhar sobre a avaliação educacional, numa perspectiva crítica que nos faça repensar a nossa práxis docente como ação-reflexão, em busca de uma transformação qualitativa de ensino-aprendizagem gerando um processo de emancipação mútua, daquele que ensina e daquele que aprende.

Quando falamos em avaliação da aprendizagem, necessário se faz, em princípio, estabelecer uma relação de cumplicidade entre essas duas palavras, posto que nos referimos a avaliação enquanto processo de ensino-aprendizagem, onde o percurso percorrido por professor e aluno torna-se, a priori, nosso referencial.

Ao recorrermos à literatura recente, algumas considerações já produzidas demonstram a preocupação em ampliar e demonstrar uma nova compreensão a respeito de avaliação da aprendizagem. Nossa inten- 
ção é de pontuar alguns acontecimentos marcantes, bem como citar alguns nomes importantes nesse movimento.

O conceito de avaliação é aqui constituído numa dimensão histórica, e como tal acompanha os movimentos e as transformações sociais, em cada época em diferentes espaços e contextos.

Segundo Abramowicz ${ }^{1}$ (1996),

"o estudo de avaliação da aprendizagem constitui-se no ramo mais antigo da área de medida do rendimento e teve início em 1901 com Robert Thorndike, nos Estados Unidos, enfatizando a medida das mudanças comportamentais".

Durante muito tempo os estudos sobre avaliação foram centrados na proposta de medir o progresso dos alunos, baseando-se em testes que eram elaborados conforme objetivos pré-definidos ou com testes padronizados. Aos poucos esses testes começaram a ser revistos na medida em que o aluno também foi deixando de ser considerado como um depositário de informações, e os procedimentos avaliativos passaram a considerar questões como opiniões, atitudes, expectativas.

É atribuído a Tyler o pioneirismo na avaliação educacional. Coube a ele inserir entre outros elementos, a definição de objetivos como comportamento manifesto do aluno no desenvolvimento curricular. Essas questões foram fundamentais na introdução de novos conceitos na avaliação da aprendizagem com ênfase na elaboração do currículo como um instrumento para regulação do conhecimento, para o controle do planejamento, para quantificar e classificar produtos e resultados. Isto tudo dentro de uma lógica tecnicista vinculada à dimensão de controle e medida. Esse modelo foi considerado na época um instrumento de possibilidade de aperfeiçoamento do ensino.

Dentro dessa corrente tecnicista, encontramos Hilda Taba, Robert F. Mager, Robert Gagné, sendo este último um propositor de que a avaliação da aprendizagem significava verificar se o "aluno conseguiu ou não realizar cada um dos comportamentos subordinados à tarefa final e que deveriam estar contidos no programa de instrução"1.

Em 1970, James Popham em colaboração com Eva Baker anunciam a idéia de que

"quando se avalia, faz-se sempre algum tipo de apreciação.

Faz-se uma estimativa ou um julgamento de valor, de algum

fenômeno e, na avaliação educacional, estamos interessa- dos em fazer apreciações acerca do mérito dos empreen-

dimentos educacionais"'.

Esta definição de avaliação como medida de alcance dos objetivos educacionais passa a ter a inclusão de outros instrumentos tais como testes cientificamente construídos, objetivando a eficiência do processo de ensino-aprendizagem como determinantes do sucesso ou fracasso educativo.

Cronbach na década de 60

\begin{abstract}
"propunha uma superação da idéia de que os objetivos são organizadores da avaliação. Para ele, a avaliação deve se orientar pela noção do tipo de decisão que se pretende que ela sirva. As decisões a serem tomadas constituem, pois, o centro da avaliação. Por isso avaliar as estruturas específicas de um programa é mais importante que fazer comparações com outras unidades externas; o processo interno é muito importante e as decisões de mudança podem ser tomadas durante o desenvolvimento, não necessariamente depois de terminado o programa de curso" 8 .
\end{abstract}

Acrescentamos a esse contexto as idéias do grupo de estudos de Bloom (1970) que apontam para a definição da avaliação tal qual vem sendo utilizada como critério de atribuição de notas ao aluno, bem como uma forma de classificá-lo. Sob a supervisão de Bloom, um grupo de estudos da Universidade de Chicago, hierarquizou as tarefas de aprendizagem com aplicação de testes de curto diagnóstico e progresso do aluno, regulando a aprendizagem dos alunos e auxiliando sua motivação. Definiram assim a avaliação da aprendizagem: "é a coleta sistemática de dados a fim de verificar se, de fato, certas mudanças estão ocorrendo no aprendiz bem como verificar a quantidade de mudança ocorrida em cada aluno"1.

Scriven (1967) foi o precursor da "clássica distinção entre avaliação formativa, que se realiza ao longo do processo com introdução de modificações, e avaliação somativa, realizada depois de terminado um processo para verificar os resultados".

Dessa forma Bloom e colaboradores na década de 70, propõem a discussão de uma visão de avaliação mais abrangente que se consolida entre outros como

\footnotetext{
"um método de coleta e processamento dos dados necessários à melhoria da aprendizagem e do ensino; inclui uma grande variedade de dados superior ao rotineiro exame escrito final; auxilia no esclarecimento das metas e objetivos
} 
educacionais importantes e consiste num processo de determinação da medida em que o desenvolvimento do aluno está se processando de maneira desejada; é um sistema de controle de qualidade pelo qual se pode determinar, a cada passo do processo ensino-aprendizagem, se está sendo eficaz ou não; e, caso não o esteja, que mudanças devem ser feitas a fim de assegurar sua eficiência antes que seja tarde demais; é um instrumento na prática educacional, que permite verificar se os procedimentos alternativos são igualmente eficazes na consecução de uma série de objetivos educacionais"'.

Fica evidente até aqui, uma forte marca da visão tecnicista que balizou todo o cenário educacional de uma época, a racionalidade técnica que enfatiza planejamento e controle do trabalho escolar gerando práticas encontradas inclusive nos dias atuais.

Esse período já é marcado por uma transição de concepções, onde se nota um avanço na direção de uma concepção subjetivista voltada para a apreensão das habilidades já adquiridas (ou em desenvolvimento).

Foi também no contexto dessa concepção que se iniciou a valorização da auto-avaliação, o estudo dos aspectos afetivos e a análise das condições emocionais que interferem na aprendizagem. Uma "avaliação centrada nas experiências e necessidades dos alunos" é o que surge no pensamento de Abramowicz quando afirma que há uma avaliação onde

\footnotetext{
"o aluno cria e a constrói, em que pode gerar ou mudar significados sobre si mesmo, sobre os outros, sobre o seu mundo, isto é, se produzindo através da auto-reflexão. A avaliação deve resultar de uma vivência, de uma prática de vida, não pode ser doada, trazida de fora para dentro"
}

Essas exposições demonstram uma forte crítica ao tecnicismo com sustentabilidade na lógica do subjetivismo e a incorporação de outros tantos fatores a uma nova dimensão de avaliação.

Esse cenário internacional é fundamentalmente movimentado com Michael Apple e Henry Giroux, na década de 80 , que muito contribuíram para a vertente da avaliação como forma de poder, colocando-a num contexto sociopolítico, histórico, como instrumento de controle social, com valores culturais, aliás, pluri, multiculturais, autoconstruída e transformadora.

O educador colabora para a construção de outros caminhos com esperança e possibilidades.

Como o grande nome precursor desses novos pa- radigmas, Paulo Freire representou e representa a busca por uma educação libertadora, que conduz à formação da consciência crítica, abordando a necessidade de estarem presentes no processo de aprendizagem questionamentos como: a quem se destina esse conhecimento? Quem são esses sujeitos? Em que realidade eles vivem? Paulo Freire aponta para a esperança, sendo essa esperança ativa, e não uma espera passiva, participação e construção coletiva numa postura democrática. Busca por uma transformação social, que só pode ter valor, se for emancipatória para uma sociedade mais justa e igualitária. Os ideais de Paulo Freire estão presentes no dia-a-dia de muitos educadores, e novos caminhos hoje valorizados e sua concepção de educação fazem parte de um universo por ele idealizado.

Atualmente surgem inúmeros autores que tratam especificamente da avaliação educacional como processo formativo. Perrenoud relata que é necessário mudar o processo de avaliação atribuindo-lhe um significado formativo; isto é mudar a escola. Alteram-se as relações com as famílias, as relações pedagógicas, a didática, os métodos de ensino. Implicará por certo em algumas exigências para os professores tais como: considerar os conhecimentos como recursos a serem mobilizados; negociar e conduzir projetos com seus alunos; adotar um planejamento flexível e indicativo e improvisar; implementar e explicitar um novo contrato didático.

\section{A AVALIAÇÃO FORMATIVA}

Segundo Dias Sobrinho ${ }^{8}$ (2003),

\footnotetext{
“a aprendizagem é uma das mais importantes dimensões da educação. Nos processos avaliativos, precisamos adotar uma perspectiva que dê conta de compreender vários aspectos da complexidade da totalidade desse fenômeno. Aprendizagem não se reduz a seus elementos visíveis, isto é, aquilo que pode ser demonstrado, e tampouco se limita aos objetivos práticos mais imediatos. Sua importância não corresponde necessariamente ao acúmulo de conteúdos e informações que possam ser postos à prova”.
}

Dentro de um paradigma dialético crítico, em que o aluno é visto como um ser histórico, construtor do seu conhecimento, que tem voz e vez, a avaliação formativa num processo continuado de aprendizagem, surge como elemento formador de um espaço ideológico gerador de consciência clara do que se está e porque está se fazendo, é um intenso processo de ir e vir, onde há valores de concretude individual, respei- 
tando a realidade de cada um em uma dimensão coletiva.

As aulas constituem-se em momentos de diálogos participativos, com comprometimento e pertinência mútua, com respeito às diferenças e às opiniões dos participantes, à valorização do aluno, onde em todo o processo é possível ver-se e rever-se.

Nela encontra-se flexibilidade - não está engessado em um programa pré-definido -; o processo é mais importante do que os produtos. A avaliação formativa aponta as causas das dificuldades e isso é possível em função das respostas contínuas às situações propostas. O erro é visto como um momento de aprendizagem, pois é importante para que a atividade atenda às necessidades do aluno. A auto-avaliação ganha importância enquanto processo de metacognição que abre espaço para a transformação emancipatória.

A avaliação formativa é toda permeada pela açãoreflexão.

Abrecht $^{2}$ (1994) afirma que

"a avaliação formativa não é uma verificação de conhecimentos. É antes o interrogar-se sobre um processo; é o refazer do caminho percorrido, para refletir sobre o processo de aprendizagem em si mesmo, sendo útil, principalmente, para levar o aluno a considerar uma trajetória e não um estado (de conhecimentos), dando sentido à sua aprendizagem e alertando-o, ao mesmo tempo, para eventuais lacunas ou falhas de percurso, levando-o a buscar - ou, nos casos de menor autonomia, a solicitar - os meios para vencer as dificuldades".

A avaliação formativa, assim posta, assume uma relação de ensino-aprendizagem, e não uma simples relação de controle como afirma Dias Sobrinho ${ }^{8}$ (2003).

\section{A IMPLEMENTAÇÃO DE UMA AVALIAÇÃO FORMATIVA}

A viabilidade de implementação de uma avaliação formativa está vinculada a outras mudanças, entre as quais iremos destacar:

\section{Articulação com o projeto político pedagógico}

Este deve ser integrador, participativo. Embora muitas vezes esse projeto seja bem feito do ponto de vista pedagógico, politicamente não é produto coletivo, gerando insatisfações. Sem a presença de um eixo organizador, ele pode se tornar fragmentado, implicando na sua não realização.
Portanto, é preciso ficar claro que alterações na avaliação significam, necessariamente, modificações no projeto político pedagógico.

\section{Trabalho coletivo}

A avaliação formativa exige que seja implantada em todas as disciplinas, pois apresenta uma orientação coletiva diferenciada voltada para a valorização do processo de aprendizagem. Se esta orientação não for implementada coletivamente, corre-se o risco de a avaliação formativa ser esvaziada na comparação com a forma tradicional de se avaliar com provas e trabalhos em momentos específicos.

\section{Contrato didático}

Esse contrato aparece como um acordo estabelecido e negociado entre as partes (professor e alunos) que trabalharão juntas. Fará parte dele combinar todo o programa de trabalho para se aprender, assim como acertar o processo de avaliação, de como alunos e professor se conscientizarão sobre as aprendizagens adquiridas e os erros a serem corrigidos imediatamente.

\section{Auto-avaliação}

Segundo Masetto ${ }^{13}$ (2003), esta pode ser entendida como

\footnotetext{
"a capacidade das pessoas de se aperceberem de seu processo de aprendizagem e serem capazes de oferecer a si mesmas as informações necessárias para desenvolver suas aprendizagens".
}

Essa auto-avaliação não pode ignorar o erro, já que este é visto numa avaliação formativa como um momento de aprendizagem, onde se faz a retomada e sua recomposição.

\section{Os instrumentos}

Numa avaliação tradicional, o mais conhecido dos instrumentos é a prova e essa é utilizada como certificação ou verificação de resultados. Ela avalia, julga e classifica o que foi ensinado e não o que foi aprendido. A prova é um relato instantâneo de um determinado momento. Esse modeloé totalmente descartado numa posição de avaliação formativa. O que se busca neste paradigma é, entre outros objetivos, o desenvolvimento de conhecimentos, habilidades e valores, e estes se mostram durante o processo de aprendizagem. Donde a necessidade de lançarmos mão de diferentes instrumentos adequados àqueles objetivos que, junta- 
mente com observação constante e comunicação permanente com os alunos nos permitam incentivar e motivar a aprendizagem esperada de forma contínua.

\section{O processo}

Como foi explicitado desde o início, a avaliação formativa ocorre num processo contínuo, onde essa travessia é o importante, todo o desenvolvimento está preocupado mais com o percurso do que com os resultados.

\section{O papel do educador}

Será o de intervir no processo de aprendizagem, com responsabilidade e comprometimento. Ajudar o aluno a apropriar-se do conhecimento construído, de lhe dar significado, de gerir diferenças, de problematizar, de motivar, de provocar; enfim, de dar condições ao indivíduo de desenvolver um pensamento e um discurso próprios.

Acima de tudo a avaliação formativa é uma atitude com vista ao crescimento mútuo.

As incertezas, as dúvidas e os medos deverão ser superados pelo desafio de um trabalho coletivo, de dimensão multilateral em busca de transformações da realidade.

\section{PROCESSO dE AVALIAÇÃO FORMATIVA EM AULA NOS CURSOS DE ODONTOLOGIA}

Cláudio de Moura Castro, em seu artigo "A cultura da repetência” (Revista Veja, 07/01/04, p. 22) tratando dos processos de avaliação no ensino fundamental e médio, nos traz à reflexão duas idéias que cabem perfeitamente ao ensino superior:

\footnotetext{
"De tempos idos, glorificamos no Brasil a 'cultura da repetência' em que a marca do ensino sério era reprovar muitos alunos" e "Precisamos abandonar a discussão bolorenta da aprovação automática versus a reprovação em massa. $\underline{\mathrm{O}}$ desafio é: melhorar a sala de aula (o grifo é nosso), de tal forma que os alunos sejam aprovados porque sabem o que precisam saber".
}

Concordamos plenamente com estas colocações aplicando-as aos cursos de graduação do ensino superior, nos quais o desafio é melhorar a sala de aula, transformando-a em ambiente de aprendizagem, de tal forma que os alunos venham a ser aprovados porque aprenderam o que precisavam aprender.

Por outro lado, se criarmos ambientes de aprendizagem em nossas aulas, mas não alterarmos o pro- cesso de avaliação, saindo de uma avaliação de provas e de notas para uma avaliação formativa, não conseguiremos que os alunos se encontrem com o professor e seus colegas nas aulas para aprenderem. Os dois movimentos precisam ser sincrônicos: inovação nos ambientes de aprendizagem e inovação no processo de avaliação.

O curso de Odontologia apresenta vários aspectos fundamentais para inovação em seu ensino:

1. Possibilidade de integrar conhecimentos, habilidades e atitudes: na clínica integrada, as atividades propiciam tal fato e a própria ficha de avaliação contempla estes objetivos. No entanto, seu preenchimento mecânico ou sem lhe dar o devido significado, torna-a sem valor como instrumento facilitador de uma avaliação formativa. Provendo-a de um sentido de incentivo à aprendizagem, seu uso na clínica integrada poderia dar nova vida a este ambiente e porque não adaptá-la também a outras disciplinas?

2. Possibilidade de integrar teoria e prática: nas práticas laboratoriais, na clínica integrada, na situação de atividades com manequins, pode-se fazer um planejamento em que os conhecimentos teóricos sejam aprendidos de forma integrada às situações concretas e práticas, da mesma disciplina e até mesmo de disciplinas afins, permitindo-se que as informações dialoguem e conversem entre si, independentemente se são ou não da mesma disciplina, e com as habilidades que permitam desenvolver. Por vezes, a teoria se antecipará à prática, outras vezes o conhecimento adquirirá significado quando produzido a partir de situações e casos concretos que estimularão os alunos a pesquisar. As diferentes modalidades de integração de teoria com a prática inspirarão diferenças no processo avaliativo contínuo, na escolha das técnicas de avaliação mais pertinentes e no aproveitamento destas técnicas para comunicação com os alunos ajudando-os a se motivarem para a aprendizagem ou corrigirem possíveis erros.

3. Possibilidade de integrar disciplinas básicas e profissionalizantes: é do conhecimento e experiência de todos os professores de Odontologia que o modelo de Flexner para o ensino médico foi muito importante para sua época, mas que nos tempos atuais ele pode ser substituído com vantagens por outros paradigmas curriculares que favoreçam a integração das áreas do conhecimento entre si e com outros objetivos de aprendizagem voltados para o desenvolvimento de habilidades e atitudes (ou 
valores). Então, por que não se alteram os currículos e as grades curriculares procurando fazer com que os dois anos de disciplinas básicas seguidos pelos demais com disciplinas profissionalizantes se transformassem em seis anos com as disciplinas integradas, de tal modo que as disciplinas básicas fossem estudadas enquanto são necessárias para as disciplinas profissionalizantes e integradamente a estas? Não se trata de afirmar a importância maior ou menor desta ou daquela disciplina, mas de se procurar a melhor maneira de os alunos aprenderem e fixarem o que for necessário. Os paradigmas de formação médica da Universidade de McMaster (Canadá) e do PBL ("problem based learning" aprendizagem baseada em problemas) aí estão há muitos anos tentando ousar modificações como estas que estamos sugerindo. E neste modelo curricular, o processo de avaliação formativa se torna necessário e mais fácil de ser implementado, pois, estaremos trabalhando com unidades de aprendizagem (incluindo conhecimentos, habilidades e atitudes) e o processo de avaliação ocorre durante as mesmas, permitindo aos alunos aprenderem ou corrigirem seus erros durante o tempo da unidade. A aprendizagem ocorre por unidades e não haverá necessidade de provas ou avaliações semestrais ou finais incluindo toda a matéria e decidindo, então, a aprovação ou não dos alunos.

4. Docentes com atividades profissionais concomitantes com a docência. Este fato que para muitos pode ser considerado como impeditivo para a docência, poderá ser visto sob outro ângulo: os docentes em atividades profissionais ampliam suas experiências que podem ser usadas para colaborar com sua docência e ampliam também as possibilidades de os alunos poderem explorar ambientes profissionais para sua aprendizagem. Aprender nestes ambientes, além de ser mais motivador para os alunos, ajuda a desenvolver sua responsabilidade profissional, observar e, em algumas situações, resolver casos concretos, interessar-se por pesquisar sobre estes casos; e a avaliação, através da observação, pode incidir sobre vários aspectos de aprendizagem oferecendo "feedback" imediato ao aluno: interesse, participação, curiosidade, pesquisa, habilidade de diagnóstico, de terapêutica, relacionamento com pacientes, encaminhamentos destes, e outros dependendo do ambiente profissional e da altura do curso em que o aluno se encontra.

Partindo destas possibilidades de inovação no ensino de Odontologia e da compreensão do processo avaliativo como integrante e motivador do processo de aprendizagem, contínuo para acompanhar a aprendizagem em todos os momentos e expresso por "feedbacks" que ajudem o aluno a aprender, poderemos analisar mais detidamente o uso pedagógico de algumas técnicas avaliativas que auxiliem no desenvolvimento da aprendizagem:

1. Casos clínicos ou casos simulados: são duas técnicas bastante utilizadas. Elas permitem dar "feedback" ao aluno sobre uma série de aspectos: domínio de informações, conceitos e teorias corretas, argumentação e fundamentação da tomada de decisão, aplicação adequada da teoria ao caso real, busca de informações quando necessário, qualidade das fontes pesquisadas, valores assumidos quando da decisão tomada. Se o estudo do caso clínico ou simulado for em dupla ou trio, podemos avaliar a capacidade de diálogo, respeito às opiniões dos outros, abertura a outras soluções, capacidade de argumentar e tomar decisão.

Trata-se de duas técnicas muito ricas, mas que precisam ser bem exploradas: o professor precisa conhecer suas possibilidades, $\mathrm{o}$ aluno precisa estar ciente de tudo o que se espera que ele aprenda ao usar esta técnica, e por isso não deve estranhar o fato de ser avaliado sobre todos os aspectos acima indicados. Mas, vale a pena observar em quanto o aluno pode crescer ao trabalhar com um caso clínico. Pode-se perceber também como fica pobre a avaliação de um caso clínico quando apenas se comenta se a solução dada está certa ou errada.

2. Nas atividades práticas com manequins e em laboratórios, a avaliação compreenderá principalmente duas técnicas: observação e entrevista oral. Tratase de uma atividade em que o mais importante é que o aluno demonstre habilidade para resolver situações patológicas no ambiente bucal. Observar como ele o faz, com que procedimentos e com que sucesso, qual sua habilidade motora, e questionamentos orais sobre a condução do processo e sua fundamentação. Quando as atividades realizadas nos manequins forem diferenciadas, ou mesmo quando forem as mesmas, após o exercício individual vale a pena uma comunicação, ainda no laboratório, entre todos os participantes daquela atividade naquele horário, o que permite uma aprendizagem mais completa e abrangente dos aspectos realizados, suas dificuldades e soluções encontradas. Acrescentando-se um debate coletivo pode-se oferecer maior número de "feedbacks" aos alunos sobre a aprendizagem esperada naquela 
atividade em manequins.

3. As atividades na clínica integrada permitem o exercício de uma avaliação formativa com a observação de como acontece a relação com o paciente; de que conhecimentos o aluno dispõe quanto ao diagnóstico, aos procedimentos, ao uso de materiais, à terapêutica exigida; quanto à habilidade de utilizar as informações para aplicá-las ao caso; quanto à destreza no manuseio dos materiais, à habilidade motora para trabalhar no espaço bucal. Também permitem observação do atendimento ao paciente, e encaminhamentos necessários ao caso. Após toda esta observação, deve-se dialogar com o aluno sobre como ele foi visto nessa atividade já profissional e oferecer-lhe as informações necessárias tanto para confirmar o que fez acertadamente como para corrigir o que não foi feito com acerto. Se na clínica integrada houver outros alunos observando seu colega, no momento do "feedback" ouvir primeiro o que os colegas têm a colocar, para só depois o professor se expressar. Em todo este tempo estamos fazendo avaliação porque estamos dando oportunidade para o aluno perceber se aprendeu o que precisava ou ainda não, e agora é o tempo de resgatar essa aprendizagem.

É muito pertinente que cada aluno tenha clareza de tudo o que se espera dele numa atividade de clínica integrada, para que ele mesmo possa fazer uma auto-avaliação sobre sua performance naquele atendimento e a expresse até mesmo antes de o professor comentar. Tal atitude em muito ajudaria o aluno a aprender a trabalhar como profissional, que sempre está se auto-avaliando em cada sessão de atendimento ao cliente.

4. O relatório é uma técnica avaliativa de grande importância quando se trata de atividades pedagógicas como estágios, visitas técnicas a consultórios, hospitais, pronto-socorros, postos de saúde, ambulatórios ou outros ambientes profissionais muito úteis à aprendizagem da Odontologia.

O relatório permite avaliar a capacidade de observação do aluno, de retirar do ambiente o maior número de informações possível, de perceber a atuação dos cirurgiões-dentistas, enfermeiros e paramédicos presentes no ambiente, de acompanhar as intervenções nos seus mais diferentes aspectos (desde o domínio de informações até a compreensão dos procedimentos e terapêuticas empregadas), de como se faz a relação do profissional da Saúde com o paciente.

A utilização do relatório como técnica avalia- tiva depende fundamentalmente de dois aspectos a serem bem trabalhados: elaboração do roteiro de observações a serem realizadas nos ambientes, em conjunto com os alunos; e o registro dessas observações feitas in loco para conhecimento dos demais colegas e do professor e para o debate e discussão delas à luz do que se está estudando nas aulas. Com o roteiro bem organizado e os registros feitos poderemos ajudar aos alunos aprenderem tudo o que acima indicamos como próprio de se aprender com esta técnica.

5. Também trabalhamos com outras técnicas avaliativas como as provas dissertativas, a prova de múltipla escolha, a prova com consulta, com relatórios de pesquisa (ou trabalhos monográficos).

Trata-se de técnicas em geral usadas para se avaliar conhecimentos. É um objetivo para cuja avaliação elas são adequadas. Só que elas podem ser usadas de uma forma parcial e como se uma substituísse a outra sem muita diferença entre elas.

A percepção da diferença entre elas faz com que a riqueza de cada uma delas possa ser melhor explorada, permitindo ao aluno aprender muito mais e melhor em cada uma delas.

Assim, vejamos: uma prova dissertativa pode ser corrigida apenas como certa ou errada quanto aos conceitos ali expressos (e isto é pouco para essa técnica), ou pode ser uma oportunidade para que o aluno aprenda a expressar seus conhecimentos certos ou incompletos ou errados, sua capacidade de síntese, seu pensamento lógico, sua clareza de redação, sua capacidade crítica (dependendo da formulação da pergunta), organização de pensamento e coerência na resposta.

Tudo isto o aluno pode aprender numa prova dissertativa, desde que tenha sido colocado para ele de forma clara que todos estes aspectos são esperados dele nessas respostas e que depois, na correção, sobre todos estes aspectos ele receba "feedback" claro e explícito do professor, ou de si mesmo ou de seus colegas.

As informações sobre o que o aluno aprendeu ou não nessas provas vai depender das formas com que se faça essa correção: claro está que se apenas for aposto à prova uma nota, praticamente nenhum "feedback" se ofereceu ao aluno; se o aluno tiver acesso às provas e puder corrigi-las juntamente com o professor e colegas avaliando todos os aspectos acima indicados, então, sem dúvida se terá construído excelente oportunidade de aprendizagem.

Uma prova de múltipla escolha não tem o mesmo 
objetivo de avaliação que uma prova dissertativa, pela razão fundamental que tal prova se destina a identificar os conhecimentos dos alunos quanto ao conjunto total das informações e conceitos de uma área. A prova de múltipla escolha faz uma varredura abrangendo todos os conceitos de uma disciplina. Isto nenhuma outra técnica tem condições de fazer. É próprio dela. Então os objetivos a serem avaliados são bem específicos: conhecimento de todos os conceitos, lógica de pensamento, raciocínio, fixação de conceitos.

Trata-se de uma prova de difícil construção para que possa atender a todos estes requisitos, superando a característica de aleatoriedade que é própria dela e permitindo se avaliar todos os itens acima indicados. Para se preparar e aplicar tal prova buscando desenvolver a aprendizagem e se oferecer um "feedback" seguro há que se aprender tecnicamente como construí-la.

A prova com consulta diferentemente de como é usada (dá-se uma prova dissertativa, facilitando ao aluno consultas durante a mesma) é uma técnica muito interessante para se avaliar atitude e comportamento profissionais. Simula a situação de um profissional que diante de um caso para o qual não tem resposta imediata, recorre à pesquisa e estudos individuais ou até mesmo à consulta de especialistas para encaminhar o caso. Trata-se de uma prova que deve ser feita fora de sala de aula, com tempo para pesquisa, envolvendo um caso para o qual o aluno não tenha resposta imediata. Quando terminada, o "feedback" deve levar em conta: a solução do problema, a justificativa e fundamentação teórica da solução encontrada, e, principalmente, a qualidade das fontes pesquisadas (se são adequadas ou inadequadas, ou se as mais importantes fontes foram consultadas ou não). Aprender a buscar a informação nova e necessária em fontes de primeira qualidade quanto à sua seriedade é um dos objetivos principais a serem aprendidos com esta técnica. Tal avaliação distingue esta técnica da prova dissertativa.

O relatório de pesquisa ou trabalhos monográficos é um tipo de técnica avaliativa muito usado na graduação. Esta atividade exige fazer uma pesquisa, levantar informações, fazer fichamentos, compará-las com outras, analisá-las, criticá-las, e por fim fazer uma redação em estilo de relatório de pesquisa, com as características de um trabalho científico, inclusive quanto à sua organização, citações, etc.

Estas atividades necessitam serem aprendidas pelos alunos, tendo o acompanhamento e orientação dos professores. De nada adiantará mandar-se os alu- nos fazerem pesquisa e apresentarem trabalho monográfico, sem orientação, pois na verdade nem sempre eles tiveram orientação para isso e, por vezes, nós professores nos entendemos desobrigados dessa orientação. Resultado: os alunos fazem trabalhos incorretos do ponto de vista de pesquisa, não têm "feedback" sobre isso e levam essa deficiência para sua vida profissional, dificultando posteriormente suas atividades de mestrado ou doutorado e sua participação em congressos e simpósios.

Quanto à avaliação desta técnica, há necessidade que o aluno seja informado de sua aprendizagem em todos os aspectos que ela envolve.

São estes alguns exemplos das técnicas que se pode usar para avaliação contínua e formativa nos cursos de graduação de Odontologia. Outras técnicas existem e merecem ser exploradas e utilizadas da mesma forma que estas que indicamos acima como exemplos. É muito interessante que se procure sempre variar as técnicas de acordo com nossos objetivos de aprendizagem e também para motivar os alunos.

No entanto, há uma condição básica para que estas técnicas possam colaborar significativamente para a aprendizagem dos alunos: que tenhamos registrado e documentado as atividades, os "feedbacks" de tal forma que estes dados possibilitem uma diálogo objetivo e claro com os alunos sobre o que aprenderam ou não, e o que será necessário fazer daqui para frente. Para isto é fundamental que o professor tenha uma ficha de cada aluno que registre os dados de cada um e seria importante que cada aluno tivesse organizado seu portfólio.

Em que consiste este portfólio? Em um arquivo, em estilo de pasta (hoje podendo ser criada em computador) onde o aluno vá arquivando todas as atividades que realiza com os respectivos "feedbacks" que permitam a ele ir construindo sua aprendizagem, aperfeiçoando suas atividades, tendo consciência de seu crescimento, dos erros cometidos e corrigidos e lhe permitindo uma auto-avaliação constante. Ao professor poderá servir para acompanhar o processo do aluno e não apenas os resultados finais.

Para encerrarmos este artigo, voltamos algumas páginas atrás, reportando-nos a Cláudio de Moura Castro que nos dizia: o importante é melhorarmos nossas aulas para que os alunos sejam aprovados porque aprenderam o que deveriam aprender.

Procuramos mostrar um pouco como se podem modificar alguns aspectos das aulas através de valorização de estratégias que trazem em seu bojo sugestões de uma avaliação formativa e contínua. Nossos leitores 
perceberam que voltamos a algumas técnicas avaliativas que são comuns, mas nem sempre utilizadas de forma a ajudar significativamente nossos alunos a desenvolverem aprendizagens mais complexas incluindo informação, habilidades e atitudes. As sugestões que fizemos vão nesse sentido. Revistas e reelaboradas, tais técnicas permitem a implantação de um sistema de avaliação formativa e contínua em cursos de graduação, buscando um nível mais elevado de aprendizagem.

Esperamos ter contribuído para reflexão sobre o processo de avaliação integrado ao processo de aprendizagem, uma das questões mais críticas de nosso sistema de ensino, e que o diálogo sobre este tema de relevância possa ter continuidade com a colaboração de nossos leitores. -

\section{REFERÊNCIAS BIBLIOGRÁFICAS}

1. Abramowicz M. Avaliando a avaliação da aprendizagem: um novo olhar. São Paulo: Lumem; 1996.

2. Abrecht R. A avaliação formativa. Porto: Edições Asa; 1994.

3. Apple M. Educação e poder. Porto Alegre: Artes Médicas; 1989.

4. Apple M. Ideologia e currículo. São Paulo: Brasiliense; 1982.

5. Cappelletti IF. Avaliação de políticas e práticas institucionais. São Paulo: Articulação Universidade Escola; 2002.

6. Cappelletti IF. Avaliação educacional: fundamentos e práticas.
São Paulo: Articulação Universidade Escola; 2001.

7. Cappelletti IF. Avaliação formativa: uma prática possível? No prelo, 2003.

8. Dias Sobrinho J. Avaliação - políticas e reformas da educação superior. São Paulo: Cortez; 2003.

9. Freire P. Pedagogia da autonomia. São Paulo: Paz e Terra; 1996.

10. Freire P. Pedagogia do oprimido. São Paulo: Paz e Terra; 1970.

11. Giroux H. Escola crítica e política cultural. São Paulo: Cortez; 1987.

12. Hadji C. A avaliação, regras do jogo. Porto: Porto Editora; 1994.

13. Masetto MT. Competências pedagógicas do professor universitário. São Paulo: Summus Editorial; 2003.

14. Nóvoa A. Avaliação em educação. Porto: Porto Editora; 1993.

15. Nóvoa A. Profissão professor. Porto: Porto Editora; 1995.

16. Perrenoud P. A profissionalização dos formadores de professores. Porto Alegre: Artmed; 2003.

17. Perrenoud P. Construir competências desde a escola. Porto Alegre: Artmed; 1999.

18. Saul AM. Avaliação emancipatória: desafio a teoria e a prática de avaliação e reformulação de currículo. São Paulo: Cortez; 1991.

Aceito para publicação em 11/2003

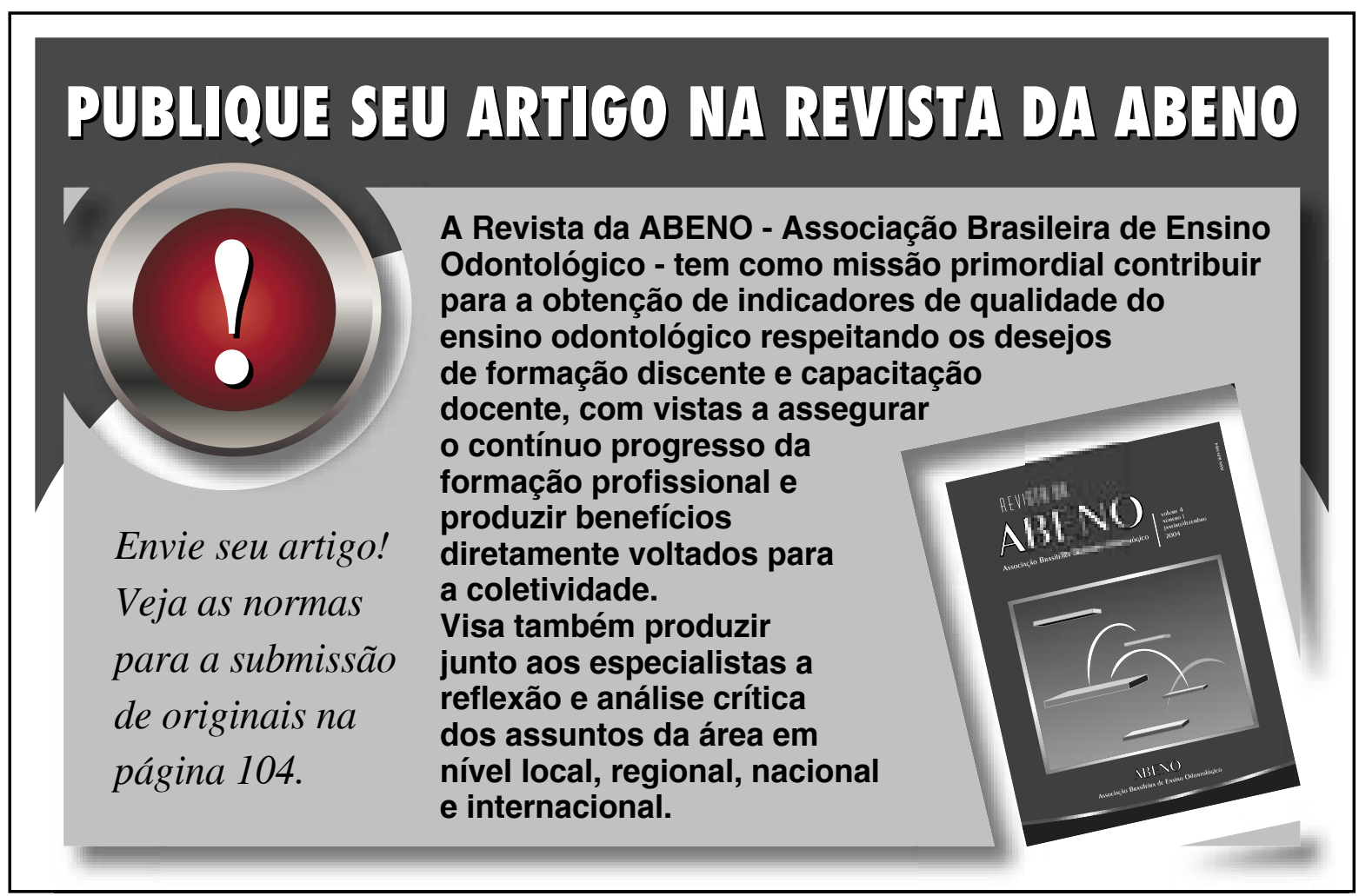

